SCIREA Journal of Biology

http://www.scirea.org/journal/Biology

December 28, 2021

Volume 6, Issue 6, December 2021

SCIREA

https://doi.org/10.54647/biology18195

\title{
Study on Bacterial Diversity and Community Structure in Grape Rhizosphere Soil Based on High-throughput Sequencing
}

\author{
FengXue ${ }^{1,2}$, TongLiu ${ }^{1, *}$ \\ ${ }^{1}$ College of Life Sciences, Shihezi University, Shihezi,832003, China; \\ ${ }^{2}$ Guilin Tourism University, Guilin Guangxi 541000, China \\ * Correspondence of email: 3555815250@qq.com
}

\begin{abstract}
:
In this study, we used the rhizosphere soil of Crimson seedless grape vines with large planting area in Shihezi, Xinjiang as research material, sequenced the bacterial 16S rRNA gene (V4) in different depths of the soil with the grape vines planted for 5, 8, 10, 12 and 15 years by using Illumina MiSeq sequencing platform, and analyzed the diversity and community structure of soil bacteria through bioinformatics related methods. The results showed that 196,690 OTUs were obtained from 45 grape vine rhizosphere soil samples, and the dominant bacterial phyla in the rhizosphere soil were Proteobacteria, Bacteroidetes, Firmicutes, Gemmatimonadetes and Actinobacteria, and the main dominant bacterial genera were Bacteroides, Sphingomonas, Prevotella_9, Lactobacillus and Enterococcus. Redundancy analysis (RDA) showed that soil total potassium and total phosphorus had the greatest influence on bacterial community structure. Correlation analysis showed that all dominant bacterial communities, except for Actinobacteria, were significantly related to soil physicochemical properties. Alpha diversity analysis showed that in $15-25 \mathrm{~cm}$ deep soil, Shannon index, Chaol and ACE indices were the
\end{abstract}


highest, indicating that layer had the highest bacterial diversity and community richness; Chaol and ACE indices of 8-year-old vine group were the highest, indicating that group had the highest bacterial community richness; so, grape vine planting years and soil depth had some influence on the diversity and richness of bacterial communities. Beta diversity and PCoA (principal coordinates analysis) analysis showed that bacterial community structure presented significant difference between different samples. Clustering results also showed that soil depth had some influence on bacterial community structure. Linear discriminant analysis suggested that the 15-year-old vine group had the highest level of biomarkers and classification, and the 15-year-old vine group also had more unique bacterial community (biomarkers) than other age groups, especially in the lower soil layer $(25-35 \mathrm{~cm})$.

Keywords: grape; rhizosphere soil; high-throughput sequencing; bacterial diversity.

\section{Introduction}

Xinjiang has a long history of grape cultivation, and it is the earliest region where grapes are planted and wine is brewed in China. The "golden" region recognized worldwide for grape growth lies between $30^{\circ}$ and $40^{\circ}$ north latitude, while Xinjiang lies between $73^{\circ} 40^{\prime}-96^{\circ} 18^{\prime}$ east longitude and $34^{\circ} 25^{\prime}-48^{\circ} 10^{\prime}$ north latitude, so the vast majority of Xinjiang is located in the golden region for grape growth. Because of its unique ecological and climatic conditions, Xinjiang is rich in high-quality grapes, which are excellent for eating directly, making raisin or making wine. As the key factor determining the value of grape products, grape quality is closely related to many ecological factors and planting techniques, and ecological factors can directly affect the diversity of soil microbial community. Soil is the basic guarantee for human survival, the "converter" of nutrient elements, the "purifier" of toxic substances and the "regulator" of ecosystem, while soil microorganisms play a leading role in these processes. The study of soil microorganisms is helpful to clarify the response of soil microorganisms to environmental changes and deepen the understanding of the relationship between aboveground and underground parts in terrestrial ecosystems ${ }^{[1]}$. Most microorganisms living in soil are bacteria, which play a key role in the growth of plants. Soil microbial diversity plays an important role in maintaining the dynamic balance of soil ecosystem and promoting the absorption and utilization of root nutrition. In turn, vines planting affect the diversity and structure of soil microorganisms by changing the soil environment ${ }^{[2]}$. As a perennial liana, 
grape vines cannot be cleared of and re-planted every year, and their fertilization and irrigation methods are limited, so the microbial diversity in grape growth soil is significantly affected $^{[3]}$. Grape growth, quality formation and immunity improvement are closely related to the community structure and quantity of microorganisms in the habitat, especially in the rhizosphere. Up to now, there are relatively few studies on bacterial diversity and colony structure in vineyard soil. Therefore, the study of bacterial diversity and community structure in vineyard soil has practical guiding significance for rationally formulating soil management measures, promoting the optimization of rhizosphere microbial structure, and achieving high yield and high quality of grapes ${ }^{[4]}$. This study aims to compare the rhizosphere bacteria of Crimson seedless vines of different ages (5 years, 8 years, 10 years, 12 years, and15 years) with large planting areas in Xinjiang, and to explore the state and diversity of microbial community structure in grape rhizosphere, so as to provide reasonable guidance for vineyard management, soil fertility improvement, yield increase, and quality enhancement.

\section{Materials and methods}

\subsection{Location}

Soil samples were taken on August 15, 2018 in the experimental base of grape planting in Shihezi Grape Research Institute, Xinjiang. The shortest age of grape vines was 5 years and the longest was 15 years. The geographical coordinates of sample taking places were $44^{\circ} 17^{\prime}$ $44^{\circ} 35^{\prime}$ north latitude, $86^{\circ} 11^{\prime}-86^{\circ} 20^{\prime}$ east longitude, and the altitude was $480 \mathrm{~m}$. The annual average temperature is $6.5-7.2^{\circ} \mathrm{C}$, the annual precipitation is $125.0-207.7 \mathrm{~mm}$, and the annual sunshine hours are $2721-2818 \mathrm{~h}$. The vineyard soil type is sandy loam, and the main cultivated variety is Crimson seedless grapes for fresh eating.

\subsection{Sample collection}

From the same variety (seedless Crimson) of grape plants with different ages $(5,8,10,12$ and 15 years), three plants were randomly selected for each age group. Around $20 \mathrm{~cm}$ from each grape plant, three points were selected take soil samples. After removing debris about $5 \mathrm{~cm}$ from the surface, the upper layer $(5-15 \mathrm{~cm})$, middle layer $(15-15 \mathrm{~cm})$ and lower layer $(25-$ $35 \mathrm{~cm}$ ) of soil were taken with earth boring augers at each point. With disposable sterilized rubber gloves, the soil was manually mixed, subpackaged and marked to make it into soil samples (about $500 \mathrm{~g}$ each) through quartering method. Each sample was divided into two parts, which were immediately put into two sterilized self-sealing bags with labels denoting 
the sampling time, place, soil depth and serial number. The samples were coded with a twodigit system, where the first digit indicated the replicate number and the second indicated the depth (1, 2 and 3 denoted the depth of 15,25 and $35 \mathrm{~cm}$, respectively). There were 5 age groups of grape vines, each group had 3 plants, and for each plant the soil was taken at three depths; so, in total there were 45 soil samples $(5 \times 3 \times 3)$. The fresh soil was immediately screened by 20 mesh sieve and divided into two parts, in which one was stored with liquid nitrogen and sent to Beijing Compass Biotechnology Co., Ltd for high-throughput sequencing, and the other was air-dried and stored for determining the physicochemical properties of soil. (See table 1 for sample coding information)

Table 1 Sample coding information

\begin{tabular}{|c|c|c|c|c|c|c|c|c|}
\hline \multicolumn{3}{|c|}{ Sample code } & \multirow{2}{*}{$\begin{array}{c}\begin{array}{c}\text { Soil } \\
\text { depth }\end{array} \\
5-15 \mathrm{~cm}\end{array}$} & \multirow[t]{2}{*}{ Age/year } & \multirow[t]{2}{*}{ Latitude } & \multirow[t]{2}{*}{ longitude } & \multirow[t]{2}{*}{ Elevation } & \multirow[t]{2}{*}{ Remarks } \\
\hline GM1.1 & GM1.2 & GM1.3 & & & & & & \\
\hline GM2.1 & GM2.2 & GM2.3 & $15-25 \mathrm{~cm}$ & 15 & & & & \\
\hline GM3.1 & GM3.2 & GM3.3 & $25-35 \mathrm{~cm}$ & & & & & \\
\hline HY1.1 & HY1.2 & HY1.3 & $5-15 \mathrm{~cm}$ & & & & & $\begin{array}{c}\text { There were } \\
5 \text { age }\end{array}$ \\
\hline HY2.1 & HY2.2 & HY2.3 & $15-25 \mathrm{~cm}$ & 10 & North & East & & $\begin{array}{c}\text { groups of } \\
\text { grape }\end{array}$ \\
\hline HY3.1 & HY3.2 & HY3.3 & $25-35 \mathrm{~cm}$ & & & & & $\begin{array}{l}\text { vines, each } \\
\text { group had }\end{array}$ \\
\hline XZ1.1 & $\mathrm{XZ1.2}$ & $\mathrm{XZ1.3}$ & $5-15 \mathrm{~cm}$ & & & & & $\begin{array}{c}3 \text { plants, } \\
\text { and for }\end{array}$ \\
\hline XZ2.1 & $\mathrm{XZ2.2}$ & $\mathrm{XZ2.3}$ & $15-25 \mathrm{~cm}$ & 8 & & & $480 \mathrm{~m}$ & $\begin{array}{c}\text { each plant } \\
\text { the soil }\end{array}$ \\
\hline XZ3.1 & $\mathrm{XZ3.2}$ & XZ3.3 & $25-35 \mathrm{~cm}$ & & & & & $\begin{array}{c}\text { was taken } \\
\text { at three }\end{array}$ \\
\hline ZN1.1 & ZN1.2 & ZN1.3 & $5-15 \mathrm{~cm}$ & & $\begin{array}{c}44^{\circ} 17^{\prime} \\
-\end{array}$ & $\begin{array}{c}86^{\circ} 11^{\prime} \\
-\end{array}$ & & $\begin{array}{c}\text { depths; so, } \\
\text { in total }\end{array}$ \\
\hline ZN2.1 & $\mathrm{ZN} 2.2$ & ZN2.3 & $15-25 \mathrm{~cm}$ & 5 & $44^{\circ} 35^{\prime}$ & $86^{\circ} 20^{\prime}$ & & $\begin{array}{c}\text { there were } \\
45 \text { soil }\end{array}$ \\
\hline ZN3.1 & ZN3.2 & ZN3.3 & $25-35 \mathrm{~cm}$ & & & & & $\begin{array}{c}\text { samples (5 } \\
\text { x } 3 \times 3) .\end{array}$ \\
\hline WH1.1 & WH1.2 & WH1.3 & $5-15 \mathrm{~cm}$ & & & & & \\
\hline WH2.1 & WH2.2 & WH2.3 & $15-25 \mathrm{~cm}$ & 12 & & & & \\
\hline WH3.1 & WH3.2 & WH3.3 & $25-35 \mathrm{~cm}$ & & & & & \\
\hline
\end{tabular}

\subsection{Determination of soil physicochemical properties properties}

The air-dried soil samples were tested for the following physicochemical indices: organic matter (SOM), total nitrogen (TN), total phosphorus (TP), total potassium (TK), nitrate nitrogen $(\mathrm{XN})$, ammonium nitrogen (AN), available phosphorus (SP), available potassium (SK), $\mathrm{pH}$ value (1:5) and electrical conductivity (EC). The soil properties were determined in 
accordance with the methods in the textbook Soil Agrochemical Analysis compiled Bao Shidan ${ }^{[5]}$. The 3 samples taken from the same layer of soil around each grape plant were mixed into one sample to determine the physicochemical properties. There were 5 ages groups, and for each group the soil involved 3 depths, so there were 15 soil samples were determined for physicochemical properties. The soil physicochemical indices were analyzed using SPSS Statistics 22.0.

\subsection{Bacterial 16S rRNA gene sequencing}

\subsubsection{DNA extraction and PCR amplification of 16s rRNA gene}

Soil genomic DNA extraction kit (centrifugal column type) was used for DNA extraction of the samples by CTAB method. Then, the purity and concentration of DNA were detected with $1 \%$ agarose gel electrophoresis. A proper amount of sample DNA was taken in a centrifuge tube, where the sample was diluted to $1 \mathrm{ng} / \mu \mathrm{l}$ with sterile water. Using diluted genomic DNA as template, specific primers with Barcode were selected according to the sequencing region to be used; Phusion ${ }^{\circledR}$ high-fidelity PCR master mix with GC buffer (New England Biolabs) was used together with NEB high-efficiency and high-fidelity enzymes to carry out PCR, so as to ensure the amplification efficiency and accuracy. The 16S rRNA gene (V4) was amplified with 515F-806R (5'-GTGCCAGCMGCCGCGGTAA-3' and 5'GGACTACHVGGGTWTCTAAT-3'), and compared with the Barcode. According to the concentration of PCR products, the samples were mixed up for isoconcentration, and then the PCR products were purified by electrophoresis with $1 \times$ TAE buffer and $2 \%$ agarose gel. The sequences with main bands between 400-450 bp were selected, and the target bands were recovered by tapping. The product purification kit we used was GeneJET gel recovery kit (Thermo Scientific). Ion plus fragment library kit 48rxns (Thermofisher) was used to construct the library, which was then quantified and qualified by Qubit, and finally sequencing was carried out with Ion S5TMXL (Thermofisher).

\subsubsection{Biological information analysis}

\section{a. sequencing data processing}

Cutadapt(V1.9.1 $)^{[6]}$ was used to cut off the low-quality part of the reads; then, based on the reads obtained from Barcode, the data for each sample were separated. After cutting off Barcode and the primer sequences, raw reads were obtained. The raw reads were then detected with UCHIME Algorithm ${ }^{[7]}$ and compared with gene annotation database to remove chimeric sequences $^{[8]}$, so as to get the final clean reads. 


\section{b. OTU clustering and annotation}

Sequence clustering was carried out to all clean reads of the samples by using Uparse v7.0.1001 ${ }^{[9]}$ at the default identity of $97 \%$ to obtain OTUs (Operational Taxonomic Units). Representative sequences were selected for the OTUs to carry out specie annotation; then, specie annotation analysis was done by using Mothur method and SILVA ${ }^{[10]}$ SSUrRNA database $^{[11]}$ to obtain taxonomic information, and the community composition of each sample was analyzed at each classification level. Using MUSCLE ${ }^{[12]}$ (Version 3.8.31) software, the phylogenetic relationships of all OTUs' representative sequences were obtained. Finally, the data of each sample were homogenized.

Qiime software (Version 1.9.1) was used to calculate OTU abundance, Alpha diversity and UniFrac distance. R software (Version 2.15.3) was used to do rarefaction curve plotting, redundancy analysis (RDA), intergroup variation analysis of Alpha diversity index, and intergroup variation analysis of Beta diversity index. LEfSe software was used for LDA Effect Size analysis at the default LDA score of 4.

\section{Results and analysis}

\subsection{Soil physicochemical properties}

The test results of physical and chemical indicators of the soil are shown in Table 2. The content of soil organic matter (SOM) was $42.102-57.650 \mathrm{~g} / \mathrm{kg}$; the contents of total nitrogen (TN), total phosphorus (TP) and total potassium (TP) in soil were $2.913-4.292 \mathrm{~g} / \mathrm{kg}, 1.081$ $1.304 \mathrm{~g} / \mathrm{kg}$ and $14.318-16.944 \mathrm{~g} / \mathrm{kg}$, respectively. The contents of nitrate nitrogen $(\mathrm{XN})$ and ammonium nitrogen (AN) in soil were $10.169-97.959 \mathrm{mg} / \mathrm{kg}$ and $7.505-23.665 \mathrm{mg} / \mathrm{kg}$, respectively. The contents of available phosphorus (SP) and available potassium (SP) were $30.393-103.853 \mathrm{mg} / \mathrm{kg}$ and $107.620-175.180 \mathrm{mg} / \mathrm{kg}$, respectively. Soil EC values ranged from $185 \mu \mathrm{s} / \mathrm{cm}$ to $454 \mu \mathrm{s} / \mathrm{cm}$. The soil $\mathrm{pH}$ value was between 7.65 and 8.02 , indicating the soil was alkaline.

The analysis of variance showed that vine age had significant effect on total potassium and available phosphorus $(\mathrm{P}<0.05)$, and root depth had significant effect on nitrate nitrogen and available potassium $(\mathrm{P}<0.05)$. Among the physicochemical indices, organic matter had a significant effect on total nitrogen and potassium $(\mathrm{P}<0.01)$, while total nitrogen had a significant effect on total potassium and nitrate nitrogen $(\mathrm{P}<0.05)$. Ammonium nitrogen was 
closely related to nitrate nitrogen $(\mathrm{P}<0.05)$, and nitrate nitrogen had a significant effect on $\mathrm{pH}$ value $(\mathrm{P}<0.05)$.

Table 2 Determined results of soil physicochemical properties

\begin{tabular}{ccccccccccc}
\hline $\begin{array}{c}\text { Sample } \\
\text { name }\end{array}$ & $\begin{array}{c}\text { age } \\
\text { Xine }\end{array}$ & SOM & TN & TP & TK & XN & AN & SP & SK & $\mathrm{pH}(1: 5)$ \\
\hline XZ1-1 & 8 & 56.114 & 3.519 & 1.190 & 14.318 & 68.682 & 12.475 & 52.012 & 169.549 & 7.650 \\
XZ2-2 & 8 & 44.901 & 3.350 & 1.218 & 16.126 & 25.951 & 7.741 & 51.353 & 134.765 & 7.960 \\
XZ3-3 & 8 & 48.673 & 3.388 & 1.081 & 15.634 & 15.752 & 13.948 & 30.393 & 109.034 & 7.970 \\
HY1-1 & 10 & 56.325 & 3.635 & 1.304 & 14.596 & 20.492 & 8.217 & 51.151 & 150.267 & 7.980 \\
HY2-2 & 10 & 48.873 & 3.099 & 1.213 & 16.137 & 10.169 & 12.223 & 60.305 & 113.655 & 8.020 \\
HY3-3 & 10 & 46.306 & 3.337 & 1.202 & 15.602 & 17.006 & 11.755 & 32.386 & 107.620 & 7.950 \\
ZN1-1 & 5 & 50.009 & 3.491 & 1.210 & 15.286 & 97.959 & 12.929 & 66.403 & 137.999 & 7.780 \\
ZN2-2 & 5 & 49.532 & 3.656 & 1.191 & 15.950 & 20.016 & 13.698 & 70.132 & 136.654 & 8.010 \\
ZN3-3 & 5 & 57.650 & 4.291 & 1.202 & 15.021 & 55.443 & 13.968 & 58.797 & 144.423 & 7.950 \\
GM1-1 & 15 & 50.192 & 3.690 & 1.181 & 16.110 & 94.021 & 23.665 & 58.070 & 175.180 & 7.930 \\
GM2-2 & 15 & 42.102 & 2.913 & 1.175 & 16.620 & 23.825 & 7.505 & 52.726 & 123.404 & 7.880 \\
GM3-3 & 15 & 47.079 & 3.279 & 1.172 & 16.944 & 31.092 & 12.941 & 66.349 & 127.107 & 7.980 \\
WH1-1 & 12 & 52.106 & 4.292 & 1.128 & 15.145 & 82.015 & 16.694 & 78.060 & 124.151 & 7.980 \\
WH2-2 & 12 & 51.632 & 3.450 & 1.273 & 15.017 & 30.671 & 14.592 & 87.228 & 123.411 & 7.990 \\
WH3-3 & 12 & 56.373 & 3.692 & 1.176 & 15.664 & 45.021 & 18.244 & 103.853 & 124.967 & 7.910 \\
\hline
\end{tabular}

Note: Vine age: the ages of grape plants; The second number of the sample No. represents different soil depths (1, 2 and 3 represent the depths of 15, 25 and $35 \mathrm{~cm}$, respectively); SOM: soil organic matter content; TN: total nitrogen content in soil; TP: total phosphorus content in soil; TK: total potassium content in soil; $\mathrm{XN}$ : nitrate nitrogen content in soil; $\mathrm{AN}$ : ammonium nitrogen content in soil; SP: available phosphorus content in soil; SK: available potassium content in soil; EC: conductivity.

\subsection{Analysis of sequencing data}

After filtering out low-quality and short sequences, 3500718 original sequences and 2784482 valid sequences were obtained from 45 soil samples, each of which has 61877 valid sequences on average, with the minimum number of 41610 and the maximum number of 78996 for each sample. Based on the abundance of OTUs at 97\% level, we used QIIME software to process the OTUs of the valid sequences, and obtained a total of 196,690 OTU classifications, among 
which the highest number of OTUs classifications in single sample were 5,538. Then, the data of all samples were statistically analyzed in the terms of soil depth, which showed that the highest abundance of bacterial species was 70,921 OTUs, occurring in the middle layer (15$25 \mathrm{~cm}$ ); the lowest abundance of bacterial species was 60,738 OTUs, occurring in the lower layer $(25-35 \mathrm{~cm})$; and the data were also analyzed in the terms of vine age, which showed that the 15-year-old vine group (GM) had the highest OTUs, which was 41783, while the 5-yearold vine group (ZN) had the lowest OTUs, which was 35729. See Table 3 for sequence number and OTU number of each soil sample, and see Table 4 for sequence number and OTU number of soil samples in terms of soil depth and vine age.

QIIME software (Version 1.9.1) was used to generate rarefaction curves for 45 samples (Fig. 1). The rarefaction curves reveals the representativeness of each sample, which can be used to evaluate whether the current sequencing depth was enough to reflect the microbial diversity contained in the community samples. It can be seen from Fig. 1 that when the sequencing amount exceeded 40,000 reads, there were still new OTUs appearing, but the curve became flat, indicating that the sampling was basically reasonable, which meant the confidence of the bacterial community structure in the real environment was relatively high and the sequencing depth can truly reflect the bacterial community diversity in the soil; in other words, the current sequencing depth was enough to reflect the diversity of bacterial communities contained in the community sample.

Table 3 Sequence number and OTU number of soil samples

\begin{tabular}{cccc}
\hline Sample_name & Total_tag & Taxon_Tag & OTU_num \\
\hline ZN1.1 & 80092 & 65906 & 5075 \\
ZN1.2 & 80114 & 68832 & 4842 \\
ZN1.3 & 80022 & 73343 & 1631 \\
ZN2.1 & 86442 & 74653 & 4988 \\
ZN2.2 & 80205 & 63175 & 5538 \\
ZN2.3 & 73134 & 61470 & 3814 \\
ZN3.1 & 87581 & 78996 & 1964 \\
ZN3.2 & 80307 & 66873 & 5457 \\
ZN3.3 & 77075 & 65333 & 2420 \\
WH1.1 & 80145 & 56823 & 5050
\end{tabular}




\begin{tabular}{|c|c|c|c|}
\hline WH1.2 & 80210 & 73321 & 2587 \\
\hline WH1.3 & 93790 & 67134 & 5293 \\
\hline WH2.1 & 80260 & 55083 & 5081 \\
\hline WH2.2 & 80065 & 67741 & 5229 \\
\hline WH2.3 & 80056 & 54780 & 4372 \\
\hline WH3.1 & 80307 & 72976 & 2092 \\
\hline WH3.2 & 77894 & 61717 & 5032 \\
\hline WH3.3 & 80323 & 63756 & 4970 \\
\hline GM1.1 & 70505 & 49359 & 4807 \\
\hline GM1.2 & 71962 & 56620 & 4879 \\
\hline GM1.3 & 77461 & 57675 & 4653 \\
\hline GM2.1 & 80025 & 62805 & 5325 \\
\hline GM2.2 & 57533 & 48800 & 2284 \\
\hline GM2.3 & 67978 & 46734 & 4413 \\
\hline GM3.1 & 80687 & 59963 & 5203 \\
\hline GM3.2 & 80179 & 57891 & 5204 \\
\hline GM3.3 & 79520 & 61695 & 5015 \\
\hline HY1.1 & 86489 & 63378 & 5194 \\
\hline HY1.2 & 80192 & 66268 & 5402 \\
\hline HY1.3 & 87013 & 64966 & 5368 \\
\hline HY2.1 & 54703 & 47374 & 3762 \\
\hline HY2.2 & 80053 & 65717 & 5178 \\
\hline HY2.3 & 80326 & 73929 & 2494 \\
\hline HY3.1 & 80062 & 71119 & 2836 \\
\hline HY3.2 & 80113 & 59049 & 5032 \\
\hline HY3.3 & 80319 & 72656 & 2755 \\
\hline XZ1.1 & 80082 & 69332 & 4470 \\
\hline $\mathrm{XZ1.2}$ & 80248 & 70308 & 3725 \\
\hline XZ1.3 & 74304 & 54404 & 4795 \\
\hline XZ2.1 & 63961 & 41669 & 4301 \\
\hline
\end{tabular}




\begin{tabular}{|c|c|c|c|}
\hline XZ2.2 & 77477 & 57168 & 5330 \\
\hline XZ2.3 & 60952 & 41610 & 4252 \\
\hline XZ3.1 & 80086 & 60298 & 4883 \\
\hline XZ3.2 & 80181 & 61700 & 5202 \\
\hline XZ3.3 & 70285 & 50083 & 4493 \\
\hline Total & 3500718 & 2784482 & 196690 \\
\hline Average & 77794 & 61877 & 4371 \\
\hline
\end{tabular}

Table 4 Sequence number and OTU number of soil samples in the terms of soil depth and vine age

\begin{tabular}{|c|c|c|c|}
\hline Sample_Name & Total_tag & Taxon_Tag & OTU_num \\
\hline Upper layer $(5-15 \mathrm{~cm})$ & 1171427 & 929734 & 65031 \\
\hline Middle layer $(15-25 \mathrm{~cm})$ & 1166733 & 945180 & 70921 \\
\hline Lower layer $(25-35 \mathrm{~cm})$ & 1162558 & 909568 & 60738 \\
\hline ZN (5-year) & 724972 & 618581 & 35729 \\
\hline XZ (8-year) & 667576 & 506572 & 41451 \\
\hline HY (10-year) & 709270 & 584456 & 38021 \\
\hline WH (12-year) & 733050 & 573331 & 39706 \\
\hline GM (15-year) & 665850 & 501542 & 41783 \\
\hline
\end{tabular}

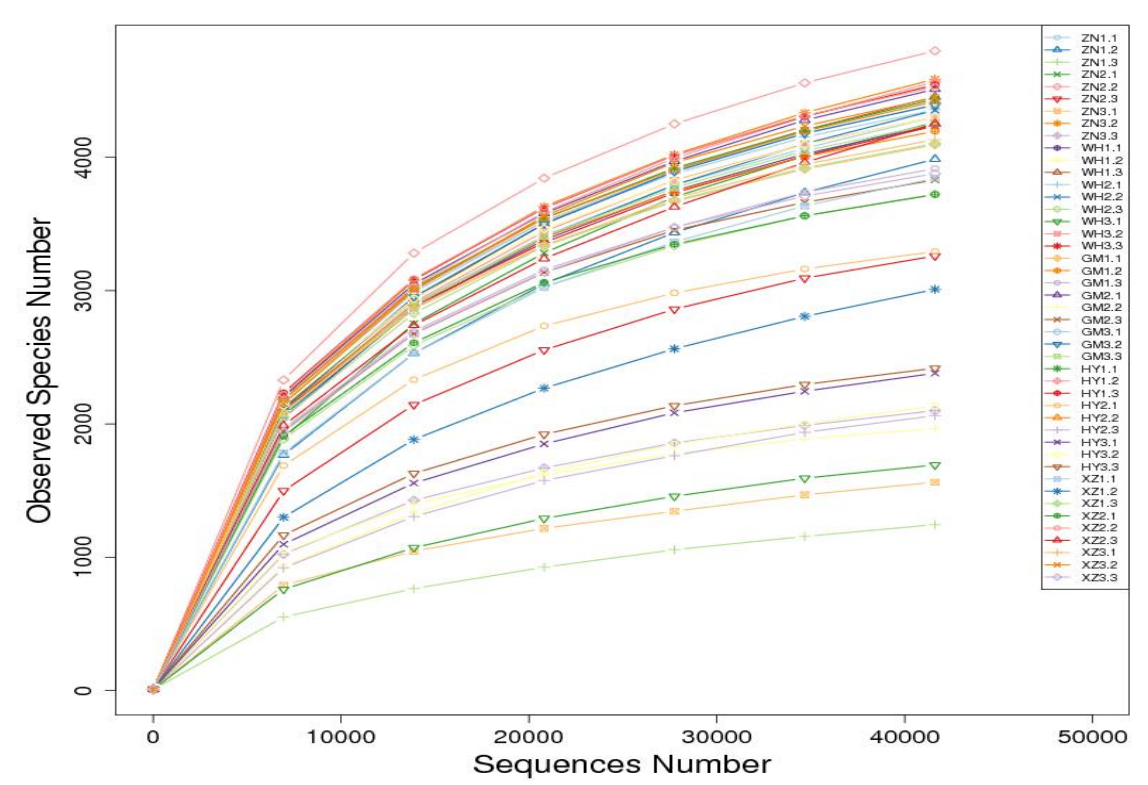

Fig. 1 Rarefaction curves at the OTUs similarity of $97 \%$ 
The OTUs similarity of the samples shown in Fig. 1 is 97\%. The abbreviations ZN, XZ, HY, WH, GM represent the vine ages of 5, 8, 10, 12 and 15 years, respectively; and the numbers 1 , 2 and 3 represent the rhizosphere soil depths of 5-15, 15-25 and 25-35 cm, respectively.

\subsection{Analysis of bacterial community structure in soil}

Fig. 2 shows the level of ten bacterial phyla in rhizosphere soil. In this study, based on the abundance from high to low, the top 10 bacterial phyla were Proteobacteria, Bacteroidetes, Firmicutes, Gemmatimonadetes, Actinobacteria, Acidobacteria, Chloroflexi, Nitrospirae, Tenericutes and Fusobacteria, accounting for 22.3\%, 14.9\%, 14.5\%, 10.1\%, 9.6\%, 6.7\%, $6.4 \%, 2.4 \%$ and 1.1 , respectively. Proteobacteria had the highest abundance in soil samples, with the abundance higher than $10 \%$.

As for the average abundance of Firmicutes, Bacteroidetes, and Fusobacteria, the 5-year-old vine group $(\mathrm{ZN})$ showed the highest value, while the 15-year-old vine group (GM) showed the lowest value, and the abundance varied greatly. The abundance of Proteobacteria did not change obviously with the vine age. There was no obvious regularity showed between the abundance changes of Actinobacteria, Chloroflexi, Nitrospirae and Tenericutes and the vine age. However, the vine age had certain influence on the abundance of Firmicutes, Bacteroidetes, Fusobacteria, Gemmatimonadetes and Acidobacteria.

In the perspective of the vertical distribution of soil, Firmicutes showed the highest abundance at 5-15 cm depth and the abundance gradually decreased with the increase of depth, while Chloroflexi and Nitrospirae showed the lowest abundance at $5-15 \mathrm{~cm}$ depth and the abundance gradually increased with the increase of depth. Gemmatimonadetes and Fusobacteria had the highest abundance at the depth of $25-35 \mathrm{~cm}$, and their abundance had little change at the depths of $5-15 \mathrm{~cm}$ and $15-25 \mathrm{~cm}$. The abundance of Actinobacteria, Proteobacteria, Bacteroidetes and Acidobacteria showed no significant relationship with soil depth. So, soil depth had some influence on the abundance of Firmicutes, Chloroflexi, Nitrospirae, Gemmatimonadetes and Fusobacteria.

Fig. 3 shows the top ten bacterial genera in rhizosphere soil. At the level of genus classification, there were many kinds of bacteria, and the unclassified bacteria with low abundance were the most important microflora, accounting for more than $90 \%$, indicating that there are a large number of unknown microbial resources to be discovered in the soil. The 10 dominant bacterial genera with high relative abundance were Bacteroides having the highest abundance (2.37\%), Sphingomonas (1.06\%), Prevost_9 (0.98\%), Lactobacillus $(0.97 \%)$, Enterococcus (0.56\%), Anaerococcus (0.36\%) Sutterella (0.31\%), Helicobacter (0.24\%), Phascolarctobacterium (0.23\%), and Butyricicoccus (0.18\%). By analyzing the sample data 
of the top three dominant bacteria, it was found that Sphingomonas had the highest abundance in the upper layer $(5-15 \mathrm{~cm})$ and the lowest abundance at the lower layer $(25-35 \mathrm{~cm})$; Prevotella_9 had the highest abundance at the lower layer $(25-35 \mathrm{~cm})$; and Bacteroides showed little difference of abundance in different layers. The analysis of variance (ANOVA) showed that the vine age had a significant effect on the abundance of Anaerotruncus $(\mathrm{P}<0.05)$, and that the soil depth had a significant effect on the abundance of Enterococcus $(\mathrm{P}<0.05)$.

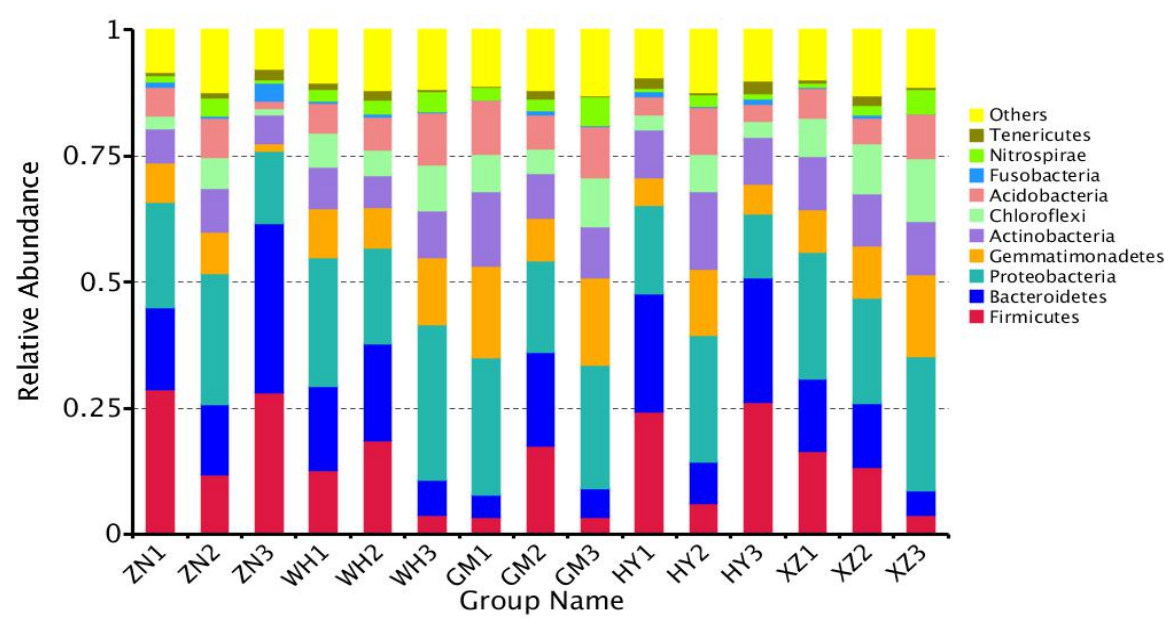

Fig. 2 The relative abundance of top ten bacterial phyla in rhizosphere soil

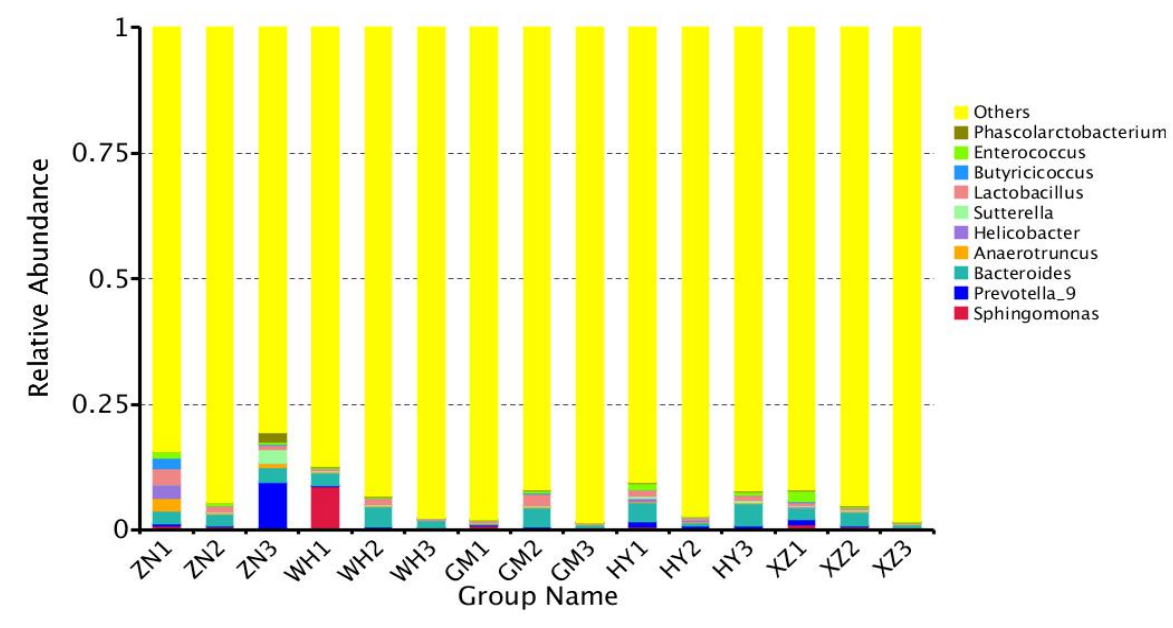

Fig. 3 The relative abundance of top ten bacterial genera in rhizosphere soil

Fig. 2 shows the relative abundance of top ten bacterial phyla in grape rhizosphere soil, and Fig. 3 shows the relative abundance of top ten bacterial genera in grape rhizosphere soil. The abbreviations ZN, XZ, HY, WH, GM represent the vine ages of 5, 8, 10, 12 and 15 years, 
respectively; and the numbers 1,2 and 3 represent the rhizosphere soil depths of 5-15, 15-25 and $25-35 \mathrm{~cm}$, respectively.

\subsection{The effect of soil physicochemical properties on bacterial community}

Redundancy analysis (RDA) at phylum level was carried out to reveal the relationship between soil physicochemical factors and bacterial community (Fig. 4). The first two axes of RDA analysis explained the $94.41 \%$ variations to the bacterial community, in which the first axis explained $91.83 \%$ and the second axis explained $2.58 \%$. Soil total potassium had the most significant effect on bacterial community, followed by soil total phosphorus, and the effects of soil physicochemical properties on bacterial community were in the order of soil total potassium $>$ total phosphorus $>$ ammonium nitrogen $>$ total nitrogen $>$ available phosphorus $>$ organic matter $>\mathrm{pH}>$ nitrate nitrogen $>$ available potassium.

Correlation analysis was made between the top 10 dominant bacterial communities (phylum level) and soil physicochemical properties (Table 5), and the results showed that all the dominant bacterial communities, except for Actinobacteria, were significantly positively related to soil physicochemical properties. Firmicutes community was positively significantly correlated with the contents of total potassium and total phosphorus $(\mathrm{P}<0.05)$; Bacteroidetes, Gemmatimonadetes and Acidobacteria communities were positively significantly correlated with total phosphorus content $(\mathrm{P}<0.05)$ and extremely significantly correlated with total potassium content $(\mathrm{P}<0.01)$; Proteobacteria community was significantly positively correlated with nitrate nitrogen content $(\mathrm{P}<0.05)$; Chloroflexi community was extremely significantly correlated with total phosphorus content $(\mathrm{P}<0.01)$ and significantly correlated with total potassium content $(\mathrm{P}<0.05)$; Fusobacteria community was significantly positively correlated with total phosphorus content $(\mathrm{P}<0.05)$; Nitrospirae community was extremely correlated with total potassium and total phosphorus $(\mathrm{P}<0.01)$; and Tenericutes was significantly positively correlated with total phosphorus content $(\mathrm{P}<0.05)$. The correlations between those dominant bacterial communities and other physicochemical properties (organic matter, total nitrogen, ammonium nitrogen, available phosphorus, available potassium and $\mathrm{pH}$ value) were not significant. 
Table 5 Correlation between dominant bacterial communities (phylum level) and soil physicochemical roperties

\begin{tabular}{ccccccccccc}
\hline & $\begin{array}{c}\text { Proteob } \\
\text { acteria }\end{array}$ & $\begin{array}{c}\text { Bactero } \\
\text { idetes }\end{array}$ & $\begin{array}{c}\text { Firmic } \\
\text { utes }\end{array}$ & $\begin{array}{c}\text { Gemmat } \\
\text { imonade } \\
\text { tes }\end{array}$ & $\begin{array}{c}\text { Actinob } \\
\text { acteria }\end{array}$ & $\begin{array}{c}\text { Acidob } \\
\text { acteria }\end{array}$ & $\begin{array}{c}\text { Chlorof } \\
\text { lexi }\end{array}$ & $\begin{array}{c}\text { Nitrospi } \\
\text { rae }\end{array}$ & $\begin{array}{c}\text { Teneri } \\
\text { cutes }\end{array}$ & $\begin{array}{c}\text { Fusoba } \\
\text { cteria }\end{array}$ \\
\hline SOM & 0.360 & 0.219 & 0.649 & 0.087 & 0.354 & 0.530 & 0.197 & 0.212 & 0.796 & 0.611 \\
$\mathrm{TN}$ & 0.161 & 0.587 & 0.865 & 0.356 & 0.347 & 0.631 & 0.361 & 0.452 & 0.956 & 0.891 \\
$\mathrm{TP}$ & 0.068 & $0.011^{*}$ & $0.027^{*}$ & $0.022^{*}$ & 0.744 & $0.038^{*}$ & $0.007^{* *}$ & $0.003^{* *}$ & $0.047^{*}$ & $0.016^{*}$ \\
$\mathrm{TK}$ & 0.552 & $0.008^{* *}$ & $0.032^{*}$ & $0.005^{* *}$ & 0.058 & $0.008^{* *}$ & $0.039^{*}$ & $0.004^{* *}$ & 0.087 & 0.149 \\
$\mathrm{XN}$ & 0.498 & 0.867 & 0.716 & 0.896 & 0.376 & 0.916 & 0.554 & 0.332 & 0.560 & 0.610 \\
$\mathrm{AN}$ & $0.028^{*}$ & 0.101 & 0.081 & 0.186 & 0.897 & 0.065 & 0.385 & 0.057 & 0.218 & 0.285 \\
$\mathrm{SP}$ & 0.193 & 0.979 & 0.610 & 0.871 & 0.325 & 0.135 & 0.782 & 0.106 & 0.534 & 0.861 \\
$\mathrm{SK}$ & 0.535 & 0.979 & 0.735 & 0.797 & 0.922 & 0.781 & 0.374 & 0.114 & 0.562 & 0.865 \\
$\mathrm{PH}$ & 0.816 & 0.966 & 0.784 & 0.777 & 0.568 & 0.689 & 0.556 & 0.152 & 0.592 & 0.623 \\
\hline
\end{tabular}

Note: * indicates significant correlation at $\mathrm{P}<0.05 ; * *$ indicates significant correlation at $\mathrm{P}<0.01$.

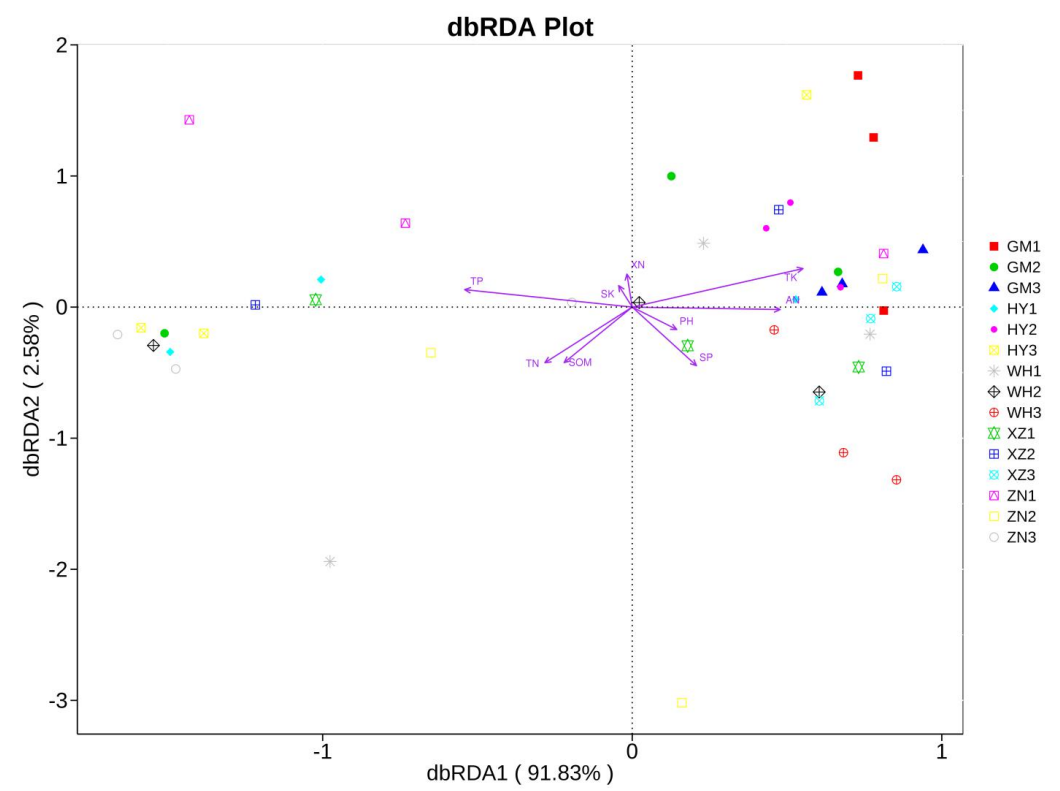

Fig. 4 Redundancy analysis of soil physicochemical properties and bacterial communities (phylum level)

The abbreviations ZN, XZ, HY, WH, GM represent the vine ages of 5, 8, 10, 12 and 15 years, respectively; and the numbers 1,2 and 3 represent the rhizosphere soil depths of 5-15, 15-25 and $25-35 \mathrm{~cm}$, respectively. 


\subsection{Analysis of soil bacterial diversity}

\subsubsection{Alpha diversity analysis}

Community richness indices Chaol and ACE and diversity indices Shannon and Simpson of each soil sample are shown in Table 6. With the increase of soil depth, Shannon index, Chao1 index and ACE index first increased and then decreased, and all the three indices showed the highest values in soil depth of $15-25 \mathrm{~cm}$, indicating that bacterial diversity and community richness were the highest in the middle layer of soil. The 15-year-old vine group had the highest Shannon index and the highest diversity of bacteria communities, while the 8-year-old vine group had the highest Chaol and ACE indices. The richness of soil bacterial species fluctuated with the planting years of grape vines, and was not distributed linearly. The result of two-way ANOVA showed that Shannon index, Simpson index, Chaol index and ACE index showed no significant difference $(\mathrm{P}>0.05)$, and the Good's coverage was between $97 \%$ and $99 \%$, indicating that the microbial species information of all the sample plots was fully reflected and the sequencing results can represent the real situation of soil bacterial communities in the vineyard sample plots.

Table 6 Alpha diversity indices of bacterial communities

\begin{tabular}{ccccccc}
\hline $\begin{array}{c}\text { Sample } \\
\text { name }\end{array}$ & $\begin{array}{c}\text { Observed } \\
\text { species }\end{array}$ & Shannon & Simpson & Chao1 & ACE & $\begin{array}{c}\text { Good's } \\
\text { coverage }\end{array}$ \\
\hline GM1 & 4332 & 10.49 & 0.998 & 5088.94 & 5213.74 & 0.97 \\
GM2 & 3517 & 9.63 & 0.995 & 3992.71 & 4174.54 & 0.98 \\
GM3 & 3998 & 10.20 & 0.997 & 4573.93 & 4764.99 & 0.98 \\
HY1 & 3369 & 9.36 & 0.994 & 4098.01 & 4098.49 & 0.98 \\
HY2 & 4428 & 10.54 & 0.998 & 5429.12 & 5507.35 & 0.97 \\
HY3 & 3007 & 8.85 & 0.991 & 3784.93 & 3804.54 & 0.98 \\
WH1 & 3429 & 9.21 & 0.988 & 4071.70 & 4220.13 & 0.98 \\
WH2 & 3596 & 9.42 & 0.993 & 4473.85 & 4558.51 & 0.98 \\
WH3 & 4137 & 10.35 & 0.998 & 5099.45 & 5131.99 & 0.97 \\
XZ1 & 3898 & 9.92 & 0.996 & 4554.28 & 4639.57 & 0.98 \\
XZ2 & 3994 & 9.87 & 0.995 & 4791.71 & 4981.00 & 0.97 \\
XZ3 & 4077 & 10.24 & 0.998 & 6729.79 & 5247.01 & 0.97 \\
ZN1 & 3376 & 9.33 & 0.993 & 4408.51 & 4437.90 & 0.98 \\
ZN2 & 4456 & 10.20 & 0.996 & 5674.08 & 5657.94 & 0.97 \\
\hline
\end{tabular}




\subsubsection{Beta diversity analysis}

Principal coordinates analysis (PCoA) was carried out to the data of bacterial communities in the soil samples to present their dispersing or clustering. As shown in Fig. 5, the contribution rate of the principal coordinate 1 ( $\mathrm{PC} 1)$ was $74.97 \%$, the contribution rate of the principal coordinate 2 (PC2) was $5.27 \%$, and their total contribution rate was $80.24 \%$. It can be seen from Fig. 6 that, except for XZ3, WH3, GM3, GM1 and HY2, which were relatively close to each other, most of the other samples were far apart, indicating that there was significant difference of bacterial community composition among the samples.

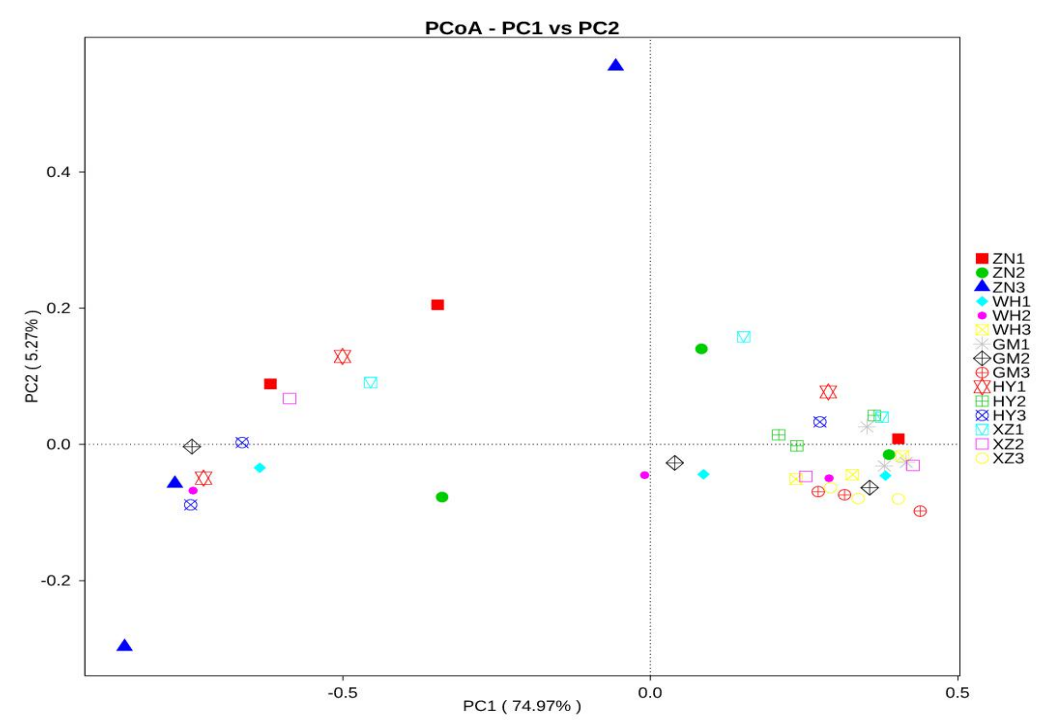

Fig. 5 PCoA analysis of soil bacterial communities

The abbreviations ZN, XZ, HY, WH, GM represent the vine ages of 5, 8, 10, 12 and 15 years, respectively; and the numbers 1,2 and 3 represent the rhizosphere soil depths of 5-15, 15-25 and $25-35 \mathrm{~cm}$, respectively.

A petal diagram can reflect the number of common and unique OTUs between groups or samples visually, for example, the overlap can presents the common OTUs between two samples. Each petal in the diagram represents a sample, and different colors represent different samples. The core number in the center represents the number of common OTUs of all samples, and the number on each petal represents the specific OTUs number of each sample. As shown in Fig. 6, the number of OTUs shared by 15 groups of samples was 1690, and the number of OTUs unique to each group of samples was quite different. The number of OTUs unique to the 5-year-old vine group (ZN1, ZN2 and ZN3) was 220, 586 and 244, respectively, accounting for $27.7 \%$ of the total OTUs number (3794), and the number of OTUs unique to the 15-year-old vine group (GM1, GM2 and GM3) was 62, 62 and 63, which were the lowest, accounting for $4.7 \%$ of the total OTUs number. 


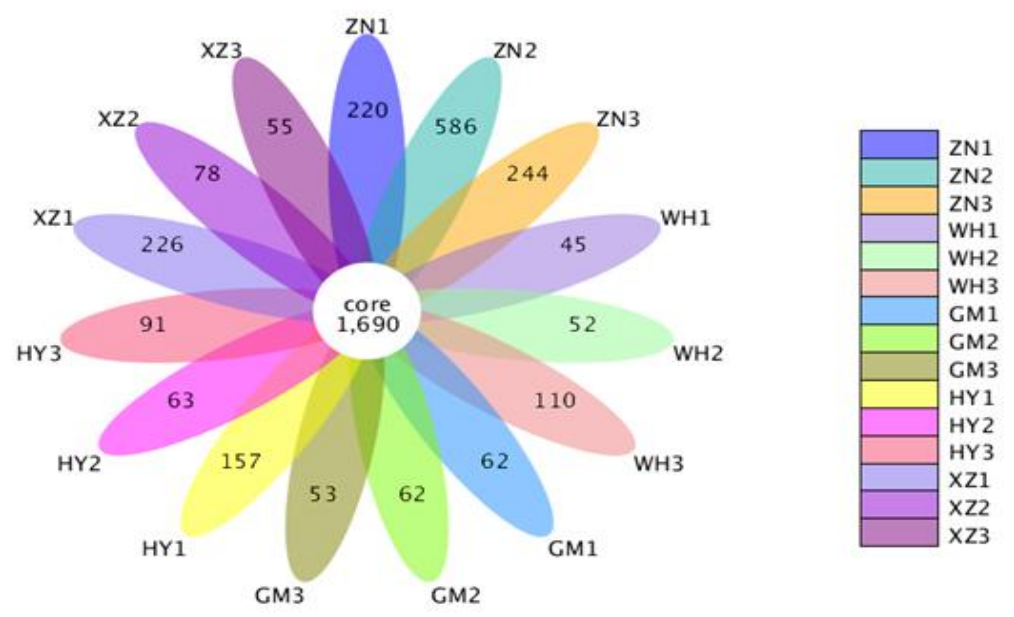

Fig. 6 OUTs-based petal diagram

The abbreviations ZN, XZ, HY, WH, GM represent the vine ages of 5, 8, 10, 12 and 15 years, respectively; and the numbers 1,2 and 3 represent the rhizosphere soil depths of 5-15, 15-25 and $25-35 \mathrm{~cm}$, respectively.

\subsubsection{Clustering analysis of sample similarity}

In order to study the similarity between different samples, we clustered the samples and constructed a sample clustering tree. As shown in Fig. 7, the bacterial communities can be divided into three taxa, where ZN3 and ZN2 were respectively clustered into one branch, and ZN1 and other samples were clustered into one big branch. ZN1, ZN2 and ZN3 represent different soil depths of 5-15, 15-25 and 25-35 cm, respectively. Each taxon came from a different soil depth, indicating that soil depth had certain effect on the bacterial community composition.
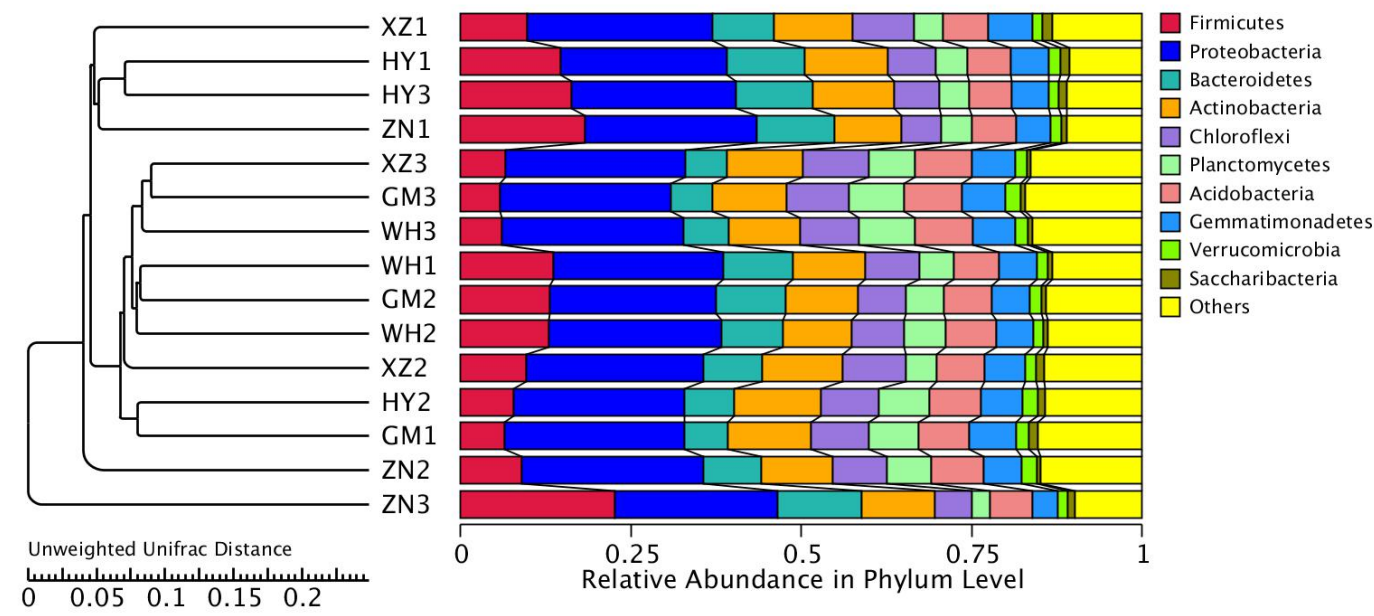

Fig. 7 UPGMA tree based on unweighted UniFrac distance at phylum level 
Note: The left part is UPGMA tree structure, and the right part is the relative abundance distribution of species at phylum level. The abbreviations ZN, XZ, HY, WH, GM represent the vine ages of 5, 8, 10, 12 and 15 years, respectively; and the numbers 1,2 and 3 represent the rhizosphere soil depths of 5-15, 15-25 and $25-35 \mathrm{~cm}$, respectively.

\subsubsection{LEfSe (LDA Effect Size) analysis}

LEfSe was used to identify bacterial species with significant differences in the terms of vine ages and soil depths. Firstly, the LEfSe analysis was carried out for samples from the same soil depth, and the LDA score of 4 was used to identify statistically significant difference between bacterial taxa. In the lower layer $(25-35 \mathrm{~cm})$, there were 21 taxa whose LDA scores were all greater than 4 , including 7 taxa of GM (15-year-old vine group), 4 taxa of $\mathrm{WH}(12-$ year-old vine group), 6 taxa of XZ (8-year-old vine group) and 4 taxa of ZN (5-year-old vine group) (Fig. 8). In the upper layer $(5-15 \mathrm{~cm})$, there were 4 taxa whose LDA scores higher than 4, including 3 taxa of WH (12-year-old vine group) and 1 taxa of XZ (8-year-old vine group) (Fig. 9).No distinct groups were observed at the middle root depth $(25 \mathrm{~cm})$.

Then, the LEfSe analysis was carried out for samples from different soil depths, the results found there were 9 bacterial taxa whose LDA scores were higher than 4 , indicating they had statistically significant difference. The 9 bacterial taxa included 6 taxa in the lower layer (25$35 \mathrm{~cm}$ ) of GM (15-year-old vine group), 1 taxon in the upper layer (5-15 cm) of GM (15-yearold vine group), 1 taxon in the lower layer $(25-35 \mathrm{~cm})$ of HY (10-year-old vine group) and 1 taxon in the middle layer $(15-25 \mathrm{~cm})$ of HY (10-year-old vine group), as shown in Fig. 10. Generally, GM (15-year-old vine group) had more biomarkers than the groups of other vine ages, especially in the lower layer $(25-35 \mathrm{~cm})$.

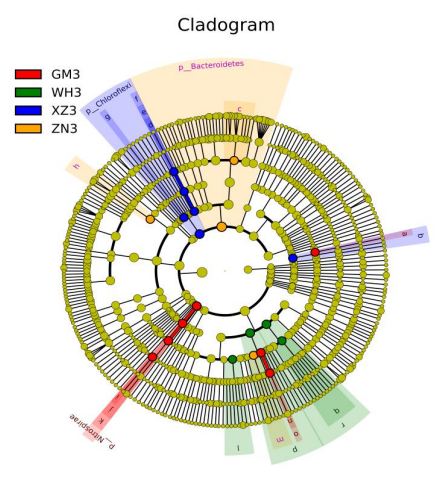

Fig. 8 Cladogram
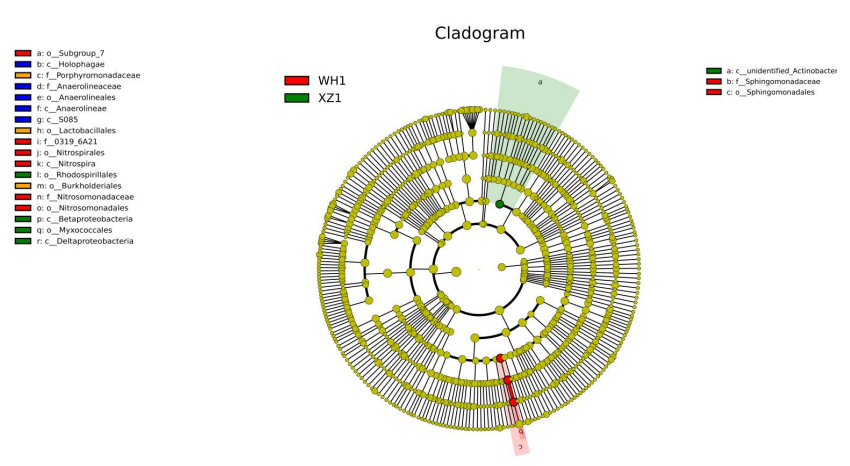

Fig. 9 Cladogram 


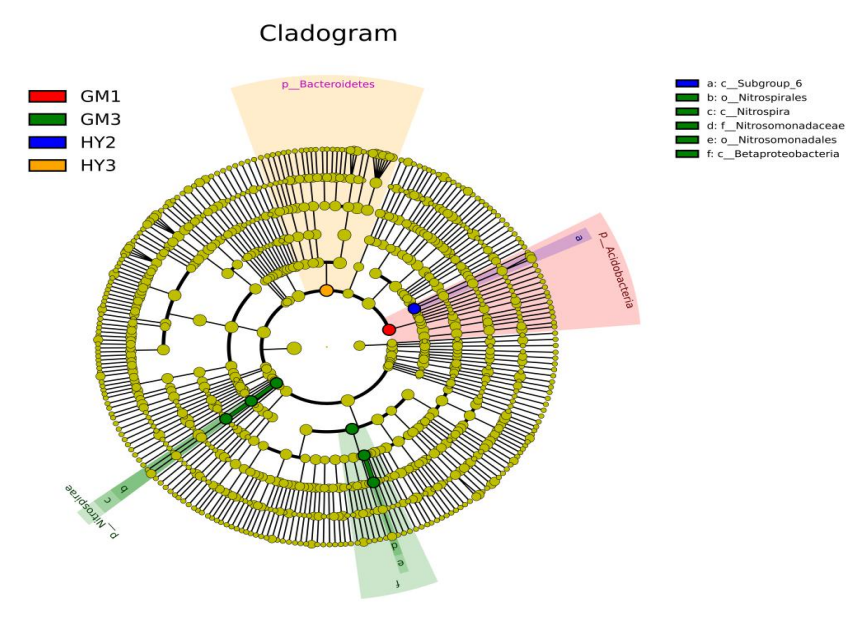

Fig. 10 Cladogram

The polygene distribution of bacterial taxa in grape rhizosphere soil was determined by using Linear Discriminant Analysis (LDA) Effect Size (LEfSe). Fig. 8 shows the bacterial taxa of the lower layer (25-35 cm); Fig. 9 shows that of the upper layer $(5-15 \mathrm{~cm})$; and Fig. 10 shows that of all the three layers $(5-15 \mathrm{~cm}, 15-25 \mathrm{~cm}$ and $25-35 \mathrm{~cm})$. In the cladograms, circles radiated from inside to outside represent the taxonomic ranks from phylum to genus (or species). Each circle at different taxonomic ranks represents a classification at that level, and the diameter of the circle is proportional to the relative abundance. The coloring principle is that the species with no significant difference are uniformly colored in yellow, and the Biomarkers of different species follow the group for coloring. The red nodes indicate the bacterial taxa that play an important role in the red group, while the green nodes indicate the bacterial taxa that play an important role in the green group. If a certain group in the picture is missing, it means that there is no species with significant difference in that group. The names of species represented by English letters in the figure are displayed in the legend on the right. The abbreviations ZN, XZ, HY, WH, GM represent the vine ages of 5, 8, 10, 12 and 15 years, respectively; and the numbers 1, 2 and 3 represent the rhizosphere soil depths of 5-15, 15-25 and $25-35 \mathrm{~cm}$, respectively. Statistically significant difference is defined by LDA $>4$.

\section{3 .Conclusion and discussion}

(1) In this study, 45 soil samples from vineyards were sequenced by $16 \mathrm{~S}$ rRNA gene highthroughput sequencing, and 196,690 OTUs were classified at 97\% similarity, indicating that there were abundant bacteria in rhizosphere microenvironment, which were not only abundant in number but also rich in species. Statistical analysis of OTUs data of different vine ages and 
different soil depths showed that the number of OTUs was the highest in the middle layer (15$25 \mathrm{~cm})$ and the lowest in the lower layer $(25-35 \mathrm{~cm})$. The number of OTUS of the vine group with longest age (15 years) was the highest, and that with the shortest age (5 years) was the lowest.

(2) The dominant bacteria in the soil samples were Proteobacteria, Bacteroidetes, Firmicutes, Gemmatimonadetes and Actinobacteria, among which the most dominant bacterial phylum was Proteobacteria which had the highest relative abundance of $22.3 \%$. The soil in the study area is alkaline, so it is speculated that Proteobacteria is the main dominant community in alkaline soil, which is consistent with many studies at home and abroad ${ }^{[16]}$. So far, the enrichment distribution of Proteobacteria has been found in the rhizosphere of $\operatorname{corn}^{[17]}$, Arabidopsis thaliana ${ }^{[18]}$, Lycium chinensis ${ }^{[19]}$, strawberry ${ }^{[20]}$, safflower carthamus ${ }^{[21]}$ and alfalfa $^{[22]}$, suggesting Proteobacteria can adapt the rhizosphere environment of many different plants. Firmicutes and Actinobacteria were also dominant phyla. Many Firmicutes can produce spores, which can resist dehydration and extreme environment, while the drought and high temperature environment of the study area was beneficial to the growth and reproduction of Firmicutes. Through the study, it was found that the abundance of Firmicutes was highest in the upper layer soil of the shortest age group, and lowest in the lower layer soil of the longest age group. Actinomycetes are an important kind of microorganisms in the rhizosphere environment of plants, and they prefer alkaline environment, while High $\mathrm{C} / \mathrm{N}$ ratio and low molecular organic matter content in soil can better promote their growth ${ }^{[23]}$. Actinomycetes can produce a large number of different antibiotics, which can regulate the biological balance among plants, pathogenic bacteria and microenvironment, which means Actinomycetes can play an important role in promoting plant growth, preventing disease ${ }^{[24-25]}$. Zhang PP et al. found that $30.9 \%$ of the Actinomycetes in the rhizosphere soil of Taxus chinensis could inhibit the activity of plant pathogenic fungi, and some of them even showed strong antibacterial activity against many plant pathogenic fungi ${ }^{[26]}$.

(3) In taxonomy of the genus, there are many kinds of bacteria, and the unclassified bacterial taxa with low abundance account for more than $90 \%$, indicating there are a large number of unknown microbial resources to be discovered. In this study, we found Bacteroides in the obvious dominant position had the highest abundance, followed by Sphingomonas. The average abundance of Bacteroides was lowest in the soil of 15-year-old vine group, and the soil depth had little effect on their abundance. With the second highest abundance only to Bacteroides, Sphingomonas had its highest abundance in the upper layer $(5-15 \mathrm{~cm})$ and the lowest abundance in the lower layer $(25-35 \mathrm{~cm})$, and the vine age had little effect on its 
abundance. Some studies pointed out that Sphingomonas are one of the most effective bacteria for degrading toxic substances in soil, they can promote nutrient absorption in grape rhizosphere and resist various pathogenic bacteria, and some of their strains had the characteristics of nitrogen fixation and dehydrogenation, thus playing an important role in maintaining soil nitrogen balance ${ }^{[27]}$.

(4) Redundancy analysis (RDA) was conducted to understand the effect of soil physicochemical properties on soil microbial communities. The results showed that soil total potassium had the most significant effect on microbial communities, followed by soil total phosphorus. Some studies have revealed that there is a certain correlation between the relative abundance of dominant bacterial communities and soil physicochemical properties ${ }^{[28-30]}$, and those environmental factors greatly affected the bacterial community composition in grape rhizosphere soil.

(5) Correlation analysis was made between the top 10 dominant bacterial communities (phylum level) and soil physicochemical properties. The results showed that there was significant correlation between soil physicochemical properties and all the dominant bacterial communities except for Actinobacteria, indicating the microbial community composition was closely related to soil environment. Some researchers pointed out that the distribution and composition of bacterial communities can be explained almost only by habitat characteristics $^{[31]}$.

(6)Alpha diversity analysis showed that Shannon index, Chaol index and ACE index were the highest in the middle layer $(15-25 \mathrm{~cm})$, indicating bacterial diversity and community richness were the highest in that soil depth. The Shannon index of 15-year-old vine group was the largest, indicating the group has the highest bacterial diversity. Chao1 and ACE indices of 8year-old vine group were the largest, indicating that group had the highest richness of bacterial communities. Generally, the depth of grape rhizosphere soil and different planting years have certain effect on the diversity and richness of bacterial communities.

(7) Beta diversity analysis and PCoA analysis showed that there were significant differences in microbial community composition among samples.

(8) LEfSe (LDA effect size) analysis showed that the vine group with longest age (15 years) in this study had more biomarkers than other groups with shorter ages, especially in the lower layer of soil. With the increase of planting years, the number of biomarkers increased, indicating that continuous cropping of grapes changed the composition of soil bacterial communities. Some studies pointed out that microbial communities in plant rhizosphere is closely related to plant growth time and root exudates ${ }^{[32-34]}$. Root exudates are the medium of 
interaction between plants and rhizosphere microorganisms, and the exudates and $\mathrm{s}$ debris from plant root activities are the main nutrient and energy sources of rhizosphere microorganisms, so root exudates are closely related to bacterial communities.

To sum up, according to the research and analysis of high-throughput sequencing, we found in grape rhizosphere soil there were a large number of bacteria, which were not only numerous, but also rich in species. Soil physicochemical properties, grape vine age and soil depth had certain effects on bacterial abundance and community composition. The vine group with longest age had more specific rhizosphere bacteria in the lower layer of soil, and the formation of those specific bacteria may be closely related to the root exudates of vine. Although the root exudates were not measured in this study, according to previous studies, the root exudates were strongly affected by the growth time and growth stage of crops, which in turn affected the succession of bacterial communities.

Although the community composition and diversity of bacteria in vineyard rhizosphere soil were analyzed by high-throughput sequencing technique, it is necessary to make a more indepth study on the changes of ecosystem functions caused by these bacteria and their abundance, as well as the interaction between rhizosphere exudates and bacteria.

\section{Acknowledgements}

This work was financially supported by the National Natural Science Foundation of China (31770461)

\section{Author Contributions}

ProfessorTongLiu and Dr Feng Xue designed the experiment. Feng Xue analyzed the data and wrote the article. HongMei Chen collected the samples.

\section{References}

[1] He Jizheng, Li Jing, Zheng Yuanming. Thoughts on the microbial diversity-stability relationship in soil ecosystems [J]. Biodiversity Science, 2013, 21(4): 411-420 (in Chinese)

[2] Yang Haijun, Xiao qiming, Liu Anyuan. Soil Microbial Diversity and Its Action [J]. Journal of Nanhua University (Science And Technology), 2005, 19(4):21-27. (in Chinese) 
[3] Liu Lingzhi, Lu Deguo, Qin Sijun. Research progress on functional microbial diversity of orchard soil ecosystem [J]. Northern Fruits, 2014(6):1-4. (in Chinese)

[4] Wang Baoli, Cen Jian, Wu Chuandong, et al. Effects of Nitrogen Form on Bacterium Diversity in Excessive Fertilization Dryland Soil [J]. Journal of Agro-Environment Science, 2011, 30(7):1351-1356. (in Chinese)

[5] Bao SD. Soil Agricultural Chemistry Analysis[M]. Beijing: China Agriculture Press, 2000: 1-114 (in Chinese)

[6] Martin M. Cutadapt removes adapter sequences from high-throughput sequencing reads[J]. Embnet Journal, 2011, 17(1) .

[7] Edgar, Robert C., et al. UCHIME improves sensitivity and speed of chimera detection. Bioinformatics 27.16 (2011): 2194-2200.

[8] Haas, Brian J., et al. Chimeric 16S rRNA sequence formation and detection in Sanger and 454-pyrosequenced PCR amplicons. Genome research 21.3 (2011): 494-504.

[9] Edgar, Robert C. UPARSE: highly accurate OTU sequences from microbial amplicon reads. Nature methods 10.10 (2013): 996-998.

[10] Wang, Qiong, et al. Naive Bayesian classifier for rapid assignment of rRNA sequences into the new bacterial taxonomy. Applied and environmental microbiology 73.16 (2007): 5261-5267.

[11] Quast C, Pruesse E, et al. The SILVA ribosomal RNA gene database project: improved data processing and web-based tools. Nucl. Acids Res. (2013) : D590-D596.

[12] MUSCLE: multiple sequence alignment with high accuracy and high throughputEdgar, 2004.

[13] Pitta DW, Pinchak E, Dowd SE, et al. Rumen bacterial diversity dynamics associated with changing from bermudagrass hay to grazed winter wheat diets. Microbial ecology 2010,59(3):511-522.

[14] Shannon CE. The mathematical theory of communication. 1963. MD computing :computers in medical practice 1997, 14(4):306-317.

[15] Lozupone C, Knight R. UniFrac: a new phylogenetic method for comparing microbial communities[J]. Applied and environmental microbiology, 2005, 71(12):8228-8235.

[16] Zhao Aihua, Du Xiaojun, Zang Jing, et al. Soil bacterial diversity in the Baotianman deciduous broad-leaved forest [J]. Biodiversity Science, 2015,23 (5): 649-657. (in Chinese) 
[17] Peiffer J A, Spor A, Koren O, et al. Diversity and heritability of the maize rhizosphere microbiome under field conditions[J]. Proceedings of the National Academy of Sciences, 2013, 110(16): 6548-6553

[18] Fierer N, Bradford M A, Jackson R B. Toward an ecological classification of soil bacteria[J]. Ecology, 2007, 88(6): 1354-1364

[19] Na Xiaofan, Zheng Guoqi, Peng Li, et al. Microbial Biodiversity in Rhizosphere of Lycium Barbarum Relative to Cultivation History [J]. Acta Soda Sinica, 2016,53 (1): 241-252. (in Chinese)

[20] Zhao Fan, Zhao Mizhen, et al. Microbial Community Structures and Diversities in Strawberry Rhizosphere Soils Based on High-throughput [J]. Soils, 2019,51 (1): 51-60. (in Chinese)

[21] Yang Meiling, Zhang Xia, Wang Shaoming et al. Analysis of bacterial community characteristics in rhizosphere soil of Yumin safflower based on high-throughput sequencing [J]. Microbiology, 2018,45 (11): 2429-2438 (in Chinese)

[22] Zhao Xiang, Liu Hongling et al. Effects of drip irrigation on bacterial diversity and community structure in rhizosphere soil of alfalfa [J]. Microbiology, 2019, 46(10): 25792590 (in Chinese)

[23] Chang Anran, Li Jia et al. Analysis of Bacterial Community Structure in Rhizosphere Soil of Tobacco based on the Metagenomics 16S rDNA Sequencing Technology [J]. Journal of Agricultural Science and Technology, 2017,19 (2): 43-50 (in Chinese)

[24] Doumbou CL, Salove MKH, Crawford DL, et al. Actinomycetes, promising tools to control plant diseases and to promote plant growth[J]. Phytoprotection, 2001, 82(3): 85144

[25] Tokala RK, Strap JL, Jung CM, et al. Novel plant-microbe rhizosphere interaction involving Streptomyces lydicus WYEC108 and the pea plant (Pisum sativum)[J]. Applied and Environmental Microbiology, 2002, 68(5): 2161-2171

[26] Zhang PP, Qin S, Yuan B, et al. Diversity and bioactivity of actinomycetes isolated from medicinal plant Taxus chinensis and rhizospheric soil[J]. Acta Microbiologica Sinica, 2016, 56(2): 241-254 (in Chinese)

[27] Shan Nana, Lai Bo. Study Progresses and Prospect on the Ecological Characteristics of Soil-inhabiting Microorganism in Soil Forming Process of Aeolian Sand Soil [J]. Environmental Protection of Xinjiang, 2004, 26(S1): 79-82. (in Chinese) 
[28] Zhu D, Zhang L, Wei ZX, et al. Effects of Bacterial manure on soil Physicochemical Properties and Microbial community diversity in Rhizosphere of Highland barley [J]. Acta Pedologica Sinica, 2014, 51(3): 627-635 (in Chinese)

[29] Lauber CL, Hamady M, Knight R, et al. Pyrosequencing-based assessment of soil $\mathrm{pH}$ as a predictor of soil bacterial community structure at the continental scale[J]. Applied Environmental Microbiology, 2009, 75(15): 5111-5120

[30] Rousk J, Bååth E, Brookes PC, et al. Soil bacterial and fungal communities across a pH gradient in an arable soil[J]. The ISME Journal, 2010, 4(10): 1340-1351

[31] Lauber CL, Hamady M, Knight R, et al. Pyrosequencing-based assessment of soil $\mathrm{pH}$ as a predictor of soil bacterial community structure at the continental scale[J]. Applied and Environmental Microbiology, 2009, 75(15): 5111-5120

[32] Wang JC, Xue C, Song Y, et al. Wheat and rice growth stages and fertilization regimes alter soil bacterial community structure, but not diversity[J]. Frontiers in Microbiology, 2016, 7: 1207

[33] Dunfield KE, Germida JJ. Diversity of bacterial communities in the rhizosphere and root interior of field-grown genetically modified Brassica napus[J]. FEMS Microbiology Ecology, 2001, 38(1): 1-9

[34] Nardi S, Concheri G, Pizzeghello D, et al. Soil organic matter mobilization by root exudates[J]. Chemosphere, 2000, 41(5): 653-658 